\title{
Fuzzy Analytical Hierarcy Process (FAHP) Ekspansi Untuk Kerangka Pengukuran Kinerja
}

\author{
Indah Purnama Sari,Herman Mawengkang ,Syahril Efendi
}

Program Studi Magister Teknik Informatika, Fakultas Ilmu Komputer dan Teknologi Informasi, Medan, Universitas Sumatera Utara

\begin{tabular}{l} 
KEYWORDS \\
\hline Fuzzy Analytic Hierarchy Process (FAHP), \\
Ekspansi, Inovasi
\end{tabular}

\section{CORRESPONDENCE}

Phone:

E-mail: indah.1804@yahoo.com

\author{
A $\mathbf{B} \quad \mathbf{S} \mathbf{T} \mathbf{R}$ A $\mathbf{C}$ T
}

Inovasi adalah prioritas atau langkah yang sangat utama bagi sebagian besar perusahaan. Kebutuhan inovasi semakin meningkat terbukti didunia perusahaan saat ini, dan tujuan inovasi adalah untuk menciptakan nilai bisnis pada suatu perusahaan. Terutama perusahaanperusahaan barat diindonesia khususnya dalam menghadapi persaingan yang tinggi karena terus menerus globalisasi. Tentu hal ini membawa fokus untuk membuat inovasi lebih komperehensif agar dapat secara efektif mengelola dan memperbaikinya. Kebutuhan akan inovasi menjadi semakin jelas diindonesia saat ini. Fuzzy Analytic Hierarchy Process (FAHP) Ekspansi adalah teknik terstruktur untuk mengatur dan menganalisis keputusan yang kompleks. Penelitian ini memberikan pedoman umum untuk mengevaluasi hubungan antara kriteria dengan menggunakan Fuzzy Analytical Hierarchy Process (FAHP)

\section{PENDAHULUAN}

\section{Latar Belakang}

Nilai-nilai inovasi dapat mengambil banyak perbedaan, seperti peningkatan inkremental produk yang sudah ada, penciptaan produk dan layanan baru atau mengurangi biaya. Perusahaan didorong untuk bertahan dan hidup tumbuh berkembang, dan didalam pasar yang berubah dengan cepat, satu-satunya cara untuk melakukan keduanya adalah berinovasi secara efektif. Tetapi kebanyakan perusahaan gagal mengimbangi bagian penting dari persamaan matriks dan pengukuran.

Hal ini disebut sebagai ketidakpastian inovasi prinsip, seperti banyak cara yang mungkin ingin dapat mengukur inovasi secara signifikan namun menghambat proses inovasi tersebut, karena inovasi melibatkan usaha kedalam hal yang tidak diketahui, dan jika kita mencoba menjabarkan ini terlalu cepat, kita mungkin membuat mereka lebih sulit untuk dikenali dan disadari. Karena inovasi tidak ada secara fisik, dan tidak ditampilkan sebagai angka yang jelas, sangat sulit untuk menentukan kriteria pengukuran. Bahkan dalam penelitian ini hanya bisa menyarankan survei dari orang-orang level CEO diperusahaan yang meluncurkan produk atau layanan inovatif. Faktanya, perusahaan yang meluncurkan produk inovatif tidak berarti demikian perusahaan inovatif dengan sendirinya. Dan dalam tulisan ini juga diterapkan untuk mengumpulkan data tidak bernomor orang, tetapi hubungan antara kriteria inovasi tidak dapat ditentukan oleh survei.

Fuzzy AHP merupakan gabungan metode AHP dengan pendekatan konsep fuzzy (Raharjo dkk, 2002). Fuzzy AHP menutupi kelemahan yang terdapat pada AHP, yaitu permasalahan terhadap kriteria yang memiliki sifat subjektif lebih banyak. Ketidakpastian bilangan direpresentasikan dengan urutan skala. Penentuan derajat keanggotaan Fuzzy AHP yang dikembangkan oleh Chang (1996) menggunakan fungsi keanggotaan segitiga (Triangular Fuzzy Number / TFN). Fungsi keanggotaan segitiga merupakan gabungan antara dua garis liniear (Jasril, etc, 2011).

Penelitian ini menargetkan untuk desain kerangka kerja kriteria kinerja inovasi dan menyediakan pedoman umum untuk mengevaluasi hubungan antara kriteria, dengan menggunakan Ekspansi Fuzzy AHP. Selain itu, penelitian ini juga memberikan pengambilan keputusan metode untuk menganalisis kinerja inovasi prioritas pengukuran terlepas dari area bisnis.

\section{Rumusan Masalah}

Berdasarkan latar belakang masalah diatas, maka penulis merumuskan masalah sebagai berikut :

1. Mengevaluasi hubungan antar kriteria dengan menggunakan Ekspansi Fuzzy AHP. 
2. Menganalisis kinerja inovasi prioritas pengukuran kriteria.

\section{Batasan Masalah}

Agar pembahasan penelitian ini tidak menyimpang daripada apa yang telah dirumuskan, maka diperlukan batasanbatasan dalam penelitian ini :

1. Metode yang digunakan Fuzzy AHP Ekspansi

2. Kriteria yang digunakan meliputi 3 aspek yaitu : pengalaman, pendidikan dan umur.

3. Perhitungan dilakukan secara manual.

\section{DTujuan Penelitian}

Berdasarkan perumusan masalah yang dibahas, maka yang menjadi tujuan dari penelitian ini adalah : Mengevaluasi hubungan antara kriteria dengan menggunakan Ekspansi Fuzzy AHP.

\section{TINJAUAN PUSTAKA}

Perbandingan Penelitian Sebelumnya dengan penelitian yang dilakukan

Penelitian yang dilakukan oleh Song - Kyoo Kim dengan judul Analytic Hierarchy Process Expansion For Innovation Performance Measurement. Penelitian ini memberikan ilustrasi tentang penggunaan metode AHP dan tahapan dalam penentuan alternatif pemilihan keputusan berdasarkan kriteria dan alternatif yang telah didefenisikan. Dalam penelitian ini Saaty menyatakan AHP merupakan suatu teori pengukuran melalui perbandingan matriks berpasangan dan mengandalkan pembobotan nilai berdasarkan skala untuk mendapatkan skala prioritas. Pertimbangan dalam pembobotan (judgement) ini dapat menjadi tidak konsisten, dan bagaimana untuk mengukur inkonsistensi yang merupakan perhatian dari konsep AHP. Skala prioritas yang telah diperoleh ini kemudian disintesis untuk mendapatkan rekomendasi keputusan.

\section{Fuzzy Analytic Hierarchy Process (FAHP)}

Dalam proses pengambilan keputusan yang melibatkan banyak kriteria, metode Fuzzy AHP dapat digunakan untuk menentukan bobot prioritas pada masing-masing kriteria yang menjadi dasar untuk analisa keputusan yang tepat. Fuzzy AHP merupakan gabungan metode AHP dengan pendekatan konsep fuzzy (Raharjo dkk, 2002). Fuzzy AHP menutupi kelemahan yang terdapat pada AHP, yaitu permasalahan terhadap kriteria yang memiliki sifat subjektif lebih banyak. Ketidakpastian bilangan direpresentasikan dengan urutan skala. Untuk menentukan derajat keanggotaan pada Fuzzy AHP, digunakan aturan fungsi dalam bentuk bilangan fuzzy segitiga atau Triangular Fuzzy Number (TFN) yang disusun berdasarkan himpunan linguistik. Jadi, bilangan pada tingkat intensitas kepentingan pada AHP ditransformasikan kedalam himpunan skala TFN.

Bilangan triangular fuzzy (TFN) meupakan teori himpunan fuzzy yang membantu dalam pengukuran yang berhubungan dengan penilaian subjektif manusia memakai bahasa atau linguistik. Inti dari fuzzy AHP terletak pada perbandingan berpasangan yang digambarkan dengan skala rasio yang berhubungan dengan skala fuzzy.
Dalam pendefinisian nilai intensitas AHP kedalam skala fuzzy segitiga dilakukan dengan cara membagi tiap himpunan fuzzy dengan 2, kecuali untuk intensitas kepentingan satu ini menurut Chang (1996) dalam pendefinisiannya tentang FAHP. Skala fuzzy segitiga yang digunakan Chang dapat dilihat pada tabel 1. berikut ini :

Tabel 1 Skala Nilai Fuzzy Segitiga

\begin{tabular}{|c|c|c|c|}
\hline $\begin{array}{l}\text { Intensitas } \\
\text { Kepentingan } \\
\text { AHP }\end{array}$ & $\begin{array}{l}\text { Himpunan } \\
\text { Linguistik }\end{array}$ & $\begin{array}{l}\text { Tri } \\
\text { Angular } \\
\text { Fuzzy } \\
\text { Number } \\
\text { (TAFN) }\end{array}$ & $\begin{array}{l}\text { Recipro- } \\
\text { cal (Keba } \\
\text { likan) }\end{array}$ \\
\hline 1 & $\begin{array}{l}\text { Perbandi- } \\
\text { ngan } \\
\text { elemen yg } \\
\text { sama }\end{array}$ & $(1,1,1)$ & $(1,1,1)$ \\
\hline 2 & $\begin{array}{l}\text { Pertenga- } \\
\text { han }\end{array}$ & $(1 / 2,1,3 / 2)$ & $(2 / 3,1,2)$ \\
\hline 3 & $\begin{array}{l}\text { Elemen } \\
\text { satu cukup } \\
\text { penting } \\
\text { dari yg } \\
\text { lainnya }\end{array}$ & $(1,3 / 2,2)$ & $(1 / 2,2 / 3,1)$ \\
\hline 4 & $\begin{array}{l}\text { Pertenga } \\
\text { han } \\
\text { elemen } \\
\text { satu lebih } \\
\text { cukup } \\
\text { penting } \\
\text { dari yg } \\
\text { lainnya }\end{array}$ & $(3 / 2,2,5 / 2)$ & $\begin{array}{l}(2 / 5,1 / 2, \\
2 / 3)\end{array}$ \\
\hline 5 & $\begin{array}{l}\text { Elemen } \\
\text { satu kuat } \\
\text { penting } \\
\text { nya dari yg } \\
\text { lain }\end{array}$ & $(2,5 / 2,3)$ & $\begin{array}{l}(1 / 3,2 / 5, \\
1 / 2)\end{array}$ \\
\hline 6 & $\begin{array}{l}\text { Pertenga } \\
\text { han }\end{array}$ & $(5 / 2,3,7 / 2)$ & $\begin{array}{l}(2 / 7,1 / 3, \\
2 / 5)\end{array}$ \\
\hline 7 & $\begin{array}{l}\text { Elemen } \\
\text { satu lebih } \\
\text { kuat } \\
\text { penting } \\
\text { nya dari yg } \\
\text { lain }\end{array}$ & $(3,7 / 2,4)$ & $\begin{array}{l}(1 / 4,2 / 7, \\
1 / 3)\end{array}$ \\
\hline 8 & $\begin{array}{l}\text { Pertenga } \\
\text { han }\end{array}$ & $(7 / 2,4,9 / 2)$ & $\begin{array}{l}(2 / 9,1 / 4, \\
2 / 7)\end{array}$ \\
\hline 9 & $\begin{array}{l}\text { Elemen } \\
\text { satu } \\
\text { mutlak } \\
\text { lebih } \\
\text { penting } \\
\text { dari yg } \\
\text { lainnya } \\
\end{array}$ & $(4,9 / 2,9 / 2)$ & $\begin{array}{l}(2 / 9,2 / 9, \\
1 / 4)\end{array}$ \\
\hline
\end{tabular}

\section{Perluasan Analytic Hierarchy Process}

Analytic Hierarchy Process (AHP) bersifat matematis sebagai alat sederhana dan dapat dijelaskan lebih efektif dengan menggunakan matriks dalam aljabar linier. Ekspansi AHP 
adalah metode diperpanjang yang memberikan penggunaan lebih fleksibel. Metode AHP klasik adalah bagian dari AHP ekspansi.

Biarkan matrix $\mathrm{C}$ menjadi relationshipmatrix dalam kriteria dan nilai $u i, j, i=1, \ldots, n, j=1, \ldots, n$ dalam matriks menunjukkan nilai berapa kali pentingnya ketika kriteria $i$ dibandingkan dengan kriteria $j$. Skala verbal AHP berkisar dari 1 hingga 9 , atau sekitar urutan besarnya:

$\mathrm{C}=\left[\begin{array}{ccc}C_{1,1} & \cdots & C_{1, n} \\ \vdots & \ddots & \vdots \\ C_{n, 1} & \cdots & C_{n, n}\end{array}\right]$

Selain itu, biarkan matriks U menjadi matriks segitiga atas itu menunjukkan kriteria hubungan:

$\mathrm{U}=\left[\begin{array}{ccc}1 & \cdots & U_{1, n} \\ \vdots & \ddots & \vdots \\ 0 & \cdots & U_{n, n-1}\end{array}\right]$

Menurut aksioma AHP bagian segitiga bawah matriks adalah refleksi dari matriks atas U.

Untuk mendapatkan skala yang dinormalisasi untuk setiap kriteria.

Dimana :

$\widetilde{C_{l, j}}=\frac{C_{i, j}}{\sum_{k=1}^{n} C_{k, j}}$

Biarkan W menjadi diagonalmatrix yang mengandung faktor beratuntuk setiap kriteria.

\section{Pengaturan Kerangka Untuk Inovasi}

Inovasi adalah prioritas atau langkah yang sangat utama bagi sebagian besar perusahaan. Kebutuhan inovasi semakin meningkat terbukti didunia perusahaan saat ini, dan tujuan inovasi adalah untuk menciptakan nilai bisnis pada suatu perusahaan. Terutama perusahaan - perusahaan barat di indonesia khususnya dalam menghadapi persaingan yang tinggi karena terus menerus globalisasi. Tentu hal ini membawa fokus untuk membuat inovasi lebih komperehensif agar dapat secara efektif mengelola dan memperbaikinya.

Nilai - nilai inovasi dapat mengambil banyak perbedaan, seperti peningkatan inkremental produk yang sudah ada, pencipataan produk dan layanan baru atau mengurangi biaya. Perusahaan didorong untuk bertahan dan tumbuhberkembang, dan didalam pasar yang berubah dengan cepat, satu - satunya cara untuk melakukan keduanya adalah berinovasi secara efektif. Tetapi kebanyakan perusahaan gagal mengimbangi bagian penting dari persamaan matriks dan pengukuran.

Hal ini disebut sebagai ketidakpastian inovasi prinsip, seperti banyak cara yang mungkin perusahaan ingin dapat mengukur inovasi secara signifikan namun menghambat proses inovasi tersebut, karena inovasi melibatkan usaha kedalam hal yang tidak diketahui, dan jika kita mencoba menjabarkan ini terlalu cepat, kita mungkin membuat mereka lebih sulit untuk dikenali dan disadari.
Karena inovasi tidak ada secara fisik, dan tidak ditampilkan sebagai angka yang jelas, sangat sulit untuk menentukan kriteria pengukuran. Bahkan dalam penelitian ini hanya bisa menyarankan survei dari orang - orang level CEO di perusahaan yang meluncurkan produk atau layanan inovatif. Faktanya, perusahaan yang meluncurkan produk inovatif tidak berarti demikian di perusahaan inovatif dengan sendirinya. Dan dalam tulisan ini juga diterapkan untuk mengumpulkan data tidak bernomor orang, tetapi hubungan antara kriteria inovasi tidak dapat ditentukan oleh survei.

\section{Pengukuran Kinerja}

Salah satu metrik inovasi terkenal oleh Anthony adalah disarankan berdasarkan pada tiga komponen yang berbeda tetapi terkait matrik terkait input, terkait proses, dan terkait keluaran. Setiap komponen berisi beberapa subkriteria untuk dievaluasi kinerja.

Input terkait tindakan tersebut adalah :

I1: Sumber daya keuangan yang didedikasikan untuk inovasi

I2: Sumber daya manusia fokus pada inovasi

I3: Pisahkan sumber daya yang dilindungi untuk inovasi non-inti

I4: Waktu manajemen senior diinvestasikan dalam pertumbuhan baru inovasi

I5: Jumlah bidang paten.

Tindakan terkait Proses.

$P 1$ : Kecepatan proses

$P 2$ : Luasnya proses pembuatan ide

P3: Saldo portofolio inovasi

$P 4$ : Kesenjangan pertumbuhan saat ini

P5: Proses, alat, dan metrik yang berbeda untuk yang berbeda jenis peluang.

\section{Ukuran Terkait-Output}

O1: Jumlah produk atau layanan baru diluncurkan

02: Porsi pendapatan dalam kategori inti dari yang baru produk

O3: Bagian laba dari pelanggan baru (atau

kesempatan)

04: Bagian laba dari kategori baru

O5: Mengembalikan investasi inovasi.

Kriteria tingkat pertama adalah Input, Proses, dan Output, dan kriteria tingkat kedua adalah subtitle dalam setiap kriteria pertama. Dari (1), matriks $\mathrm{C}$ adalah matriks 3-oleh-3 dan memecahkan oleh-1 matriks W. Dalam hal kriteria tingkat kedua bisa direpresentasikan sebagai matriks 5-oleh-5 $\mathrm{S} u, u=1, \ldots$, 5. Setelah menghitung dengan menggunakan aljabar linier dari (1) - (15), empat 5- oleh - 1 matriks dihasilkan, dan nilai bobot kriteria adalah terkandung, dan kriteria tingkat kedua yang memilikinilai tertinggi adalah yang paling penting.

\section{Penentuan Variabel}

Hal yang sangat penting dalam penggunaan metode fuzzy $A H P$ adalah penentuan aspek-aspek apa saja yang akan digunakan sebagai perbandingan. Dalam penelitian ini, terdapat 3 aspek penilaian yang digunakan, yaitu : 
1. Aspek Pengalaman

2. Aspek Pendidikan

3. Aspek Umur

\section{METODOLOGI PENELITIAN} adalah :

Langkah-langkah yang akan dilakukan dalam penelitian ini

a. Menentukan permasalahan utama yaitu

b. Menentukan kriteria yang digunakan meliputi 3 aspek, yaitu : Pengalaman, Pendidikan dan Umur

c. Melakukan pengumpulan, dan entry data

d. Melakukan input matriks perbandingan

e. Menentukan nilai sintesis fuzzy (si) prioritas

f. Mendefenisikan nilai vector (v)

g. Mendefenisikan nilai ordinat dan bobot vector

h. Normalisasi bobot vector atau bobot prioritas kriteria yang telah diperoleh

\section{Data yang Digunakan}

Teknik yang digunakan peneliti dalam pengumpulan data, yaitu : Studi pustaka yaitu pengumpulan data dengan cara melakukan studi, analisis dan dokumentasi literatur, dan sumber catatan lain baik online maupun offline yang berkaitan dengan permasalahan yang dibahas.

\section{PEMBAHASAN DAN HASIL}

Tahapan atau langkah yang dilakukan adalah dengan mengikuti tahapan pada F-AHP, diantanya dimulai dari bagian awal hingga akhir. Adapun penyelesaianmasalah atau langkahlangkah penyelesaiannya adalah sebagai berikut :

\section{Membuatnya menjadi suatu hirarki masalah}

Untuk itu sebelum masuk ke penghitungan F-AHP, struktur hirarki pada masalah di atas dapat diselesaikan terlebih dahulu dengan menggunakan penghitungan AHP yang berguna untuk menemukan konsistensi nilai matriks perbandingannya. Input nilai matriks perbandingan AHP sebagai berikut.

Tabel 2 Matriks Perbandingan

\begin{tabular}{|l|l|l|l|}
\hline & $\mathrm{C} 1$ & $\mathrm{C} 2$ & $\mathrm{C} 3$ \\
\hline $\mathrm{C} 1$ & 1 & 3 & 5 \\
\hline $\mathrm{C} 2$ & $1 / 3$ & 1 & 3 \\
\hline $\mathrm{C} 3$ & $1 / 5$ & $1 / 3$ & 1 \\
\hline Jumlah & 1.533 & 4.333 & 9 \\
\hline
\end{tabular}

Nilai inputan perbandingan matriks di atas kemudian diproses untuk mencari bobot vektor prioritas, lamda, CI, dan CR. Sebelum menghitung nilai bobot prioritas, setiap sel pada kolom matriks dibagi dengan jumlah kolom pada tiap selnya.

Untuk kolom pertama :

$$
\begin{aligned}
& \mathrm{C} 1=\frac{1}{1.533}=0.6522 \\
& \mathrm{C} 2=\frac{1 / 3}{1.533}=0.2174 \\
& \mathrm{C} 3=\frac{1 / 5}{1.533}=0.1304
\end{aligned}
$$

Untuk kolom kedua :

$\mathrm{C} 1=\frac{3}{4.333}=0.692$

$\mathrm{C} 2=\frac{1}{4.333}=0.231$

$\mathrm{C} 3=\frac{1 / 3}{4.333}=0.077$

Untuk kolom ketiga :

$\mathrm{C} 1=\frac{5}{9}=0.556$

$\mathrm{C} 2=\frac{3}{9}=0.333$

$\mathrm{C} 3=\frac{1}{9}=0.111$

Menghitung nilai bobot prioritas yaitu untuk hasil pembagian sel yang telah diperoleh pada setiap baris matriks dijumlahkan, kemudian dibagi dengan banyaknya sel pada baris tersebut (banyak kriteria $=3$ ).

Tabel 3 Bobot Prioritas

\begin{tabular}{|l|l|l|l|l|}
\hline & $\mathrm{C} 1$ & $\mathrm{C} 2$ & $\mathrm{C} 3$ & $\begin{array}{l}\text { Bobot Prioritas } \\
\text { (Eigen vector) }\end{array}$ \\
\hline $\mathrm{C} 1$ & 0.652 & 0.692 & 0.556 & 0.633 \\
\hline $\mathrm{C} 2$ & 0.217 & 0.231 & 0.333 & 0.260 \\
\hline C3 & 0.130 & 0.077 & 0.111 & 0.106 \\
\hline & & & & 1 \\
\hline
\end{tabular}

Menghitung bobot prioritas (Ev) :

$$
\begin{aligned}
& \mathrm{C} 1=\frac{0.652+0.692+0.556}{3}=0.633 \\
& \mathrm{C} 2=\frac{0.217+0.231+0.333}{3}=0.260 \\
& \mathrm{C} 3=\frac{0.130+0.077+0.111}{3}=0.106
\end{aligned}
$$

Menghitung nilai lamda yaitu mengalikan eigenvector dan jumlah kolom sel pada tabel diatas dan menghitung nilai CI dan CR.

$$
\begin{aligned}
\text { imaks } & =(0.633 \times 1.533)+(0.260 \times 4.33)+(0.106 \times 9) \\
& =3.0554 \\
C I & =0.0277(n=3, R I=0.58), \text { dipeoleh nilai } C R \\
C R & =0.0477 \text { (Konsisten) }
\end{aligned}
$$

Menentukan nilai sintesis fuzzy (Si) prioritas.

Dengan persamaan rumus. Hasil pengolahan tabel di atas, dapat diperoleh nilai sintesis seperti tabel di bawah ini. 
Tabel 4 Nilai Sintesis Fuzzy (Si)

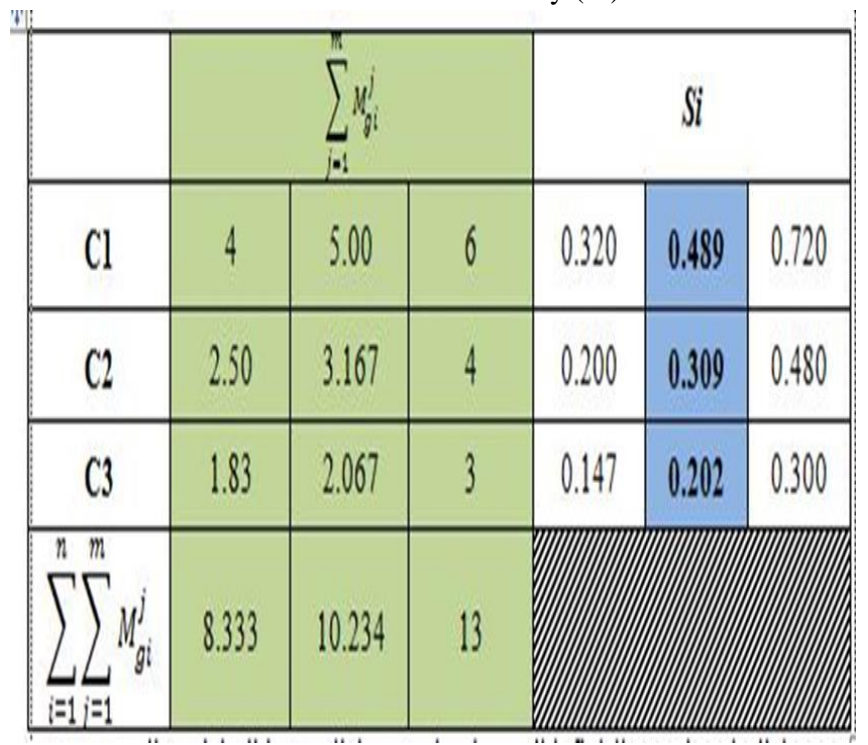

Jika telah didapat nilai Si, maka dapat didefinisikan sebagai nilai vector $(V)$
a. $\quad \mathrm{Vsc} 1 \geq(\mathrm{Vsc} 2, \mathrm{Vsc} 3)$
$\mathrm{Vsc} 1 \geq \mathrm{Vsc} 2=1$
$\mathrm{Vsc} 1 \geq \mathrm{Vsc} 3=1$
b. $\quad$ Vsc2 $\geq($ Vsc1, Vsc3)
$\mathrm{Vsc} 2 \geq \mathrm{Vsc} 1=0.472$
$\mathrm{Vsc} 2 \geq \mathrm{Vsc} 3=1$
c. $\quad \mathrm{Vsc} 3 \geq(\mathrm{Vsc} 1, \mathrm{Vsc} 2, \mathrm{Vsc} 4)$
$\mathrm{Vsc} 3 \geq \mathrm{Vsc} 1=0$
$\mathrm{Vsc} 3 \geq \mathrm{Vsc} 2=0.482$

Mendefinisikan nilai ordinat dan bobot vektor ( $\left.W^{\prime}\right)$

$$
\begin{aligned}
& \text { a. } d^{\prime}(V s c 1)=\min (1,1,1)=\mathbf{1} \\
& \text { b. } d^{\prime}(V s c 2)=\min (0.472,1)=\mathbf{0 . 4 7 2} \\
& \text { c. } d^{\prime}(V s c 3)=\min (0,0.482)=\mathbf{0} \\
& \text { Sehingga } W^{\prime}=(1,0.472,0)
\end{aligned}
$$

\section{Normalisasi bobot vector (W) atau bobot prioritas kriteria yang telah diperoleh}

$$
W=(0.679,0.321,0)^{\mathrm{T}}
$$

Diperoleh bobot prioritas kriteria yaitu $0.679,0.321,0$.

\section{KESIMPULAN DAN SARAN}

\section{Kesimpulan}

Penelitian ini mengusulkan versi fuzzy AHP yang ditingkatkan untuk memberikan fleksibilitas yang cukup untuk diterapkan dalam menganalisis inovasi ukuran kinerja dan pedoman cara menangani situasi nyata. Metodologi pengukuran inovatif ini akan

memberikan analisis yang lebih cocok untuk menentukan faktor pengukuran yang lebih penting untuk mengelola inovasi. Padahal kinerja inovasi bisa tidak diukur karena kurangnya data, penelitian ini cukup berharga untuk menyiapkan kerangka inovasipengukuran kinerja. Mengumpulkan data dari dunia nyata industri akan menjadi topik untuk studi lebih lanjut selanjutnya.

\section{Saran}

Peneliti menyarankan agar kasus ini lebih dikembangkan dengan metode yang berbeda. Dan peneliti berharap untuk pembahasan berikutnya agar dikembangkan lebih lanjut dengan mengumpulkan data dari dunia nyata industri, agar bisa menjadi topik pembahasan selanjutnya.

\section{REFERENSI}

[1] Turban, E; \& Aronson, J. 2001. Decision Support Systems and Intelligent Systems; 7th edition. New Jersey: Prentice Hall.

[2] Alonso, J.A., 2006. Consistency in The Analytic Hierarchy Pocess (AHP) : A New Approach. International Journal of Uncertainly, Fuzziness ang Knowledge-Based Systems 14 (4), 445-459.

[3] Beynon, M., 2001. DS/AHP Method : A Mathematical Analysis, including an Undestanding of Uncertainly, Ueropean Journal of Operation Research 140, 148-164.

[4] Coyle, G., 2004. Practical Strategi : The Analytical Hierarchy Process (AHP), Open Acces Material, Pearson Education Limited.

[5] Forgionne, G. A., 2002. An Architecture for the Intregration of Decision Making Support Functionalities, Idea Group Publishing, London.

[6] Arifin, Z., 2010., Penerapan Metode Analytical Hierarchy Process (AHP) untuk menentukan Sisa Hasil Usaha Pada Koperasi Pegawai Negri, Jurnal Informatika Mulawarman, vol 5 No. 2 Juli 2010.

[7] Rauter,M., 1995. About a Framework for Information and Information Processing of Learning System, Prooceedings of the IFIP International Working Conference on Information System Concepts, 54-69.

[8] Nasibu, Z., 2009., Penerapan Metode AHP Dalam Sistem Pendukung Keputusan Penempatan Karyawan Menggunakan Aplikasi Expert Choice, Jurnal Pelangi Ilmu Volume 2 No. 5 Mei 2009.

[9] T. L. Saaty, The Analytic Hierarchy Process, McGrawHill InternationalBook, New York, NY,USA, 1980.

[10] T. L. Saaty, "Axiomatic foundation of the analytic hierarchy process," Management Science, vol. 32, no. 7, pp. 841-855, 1986.

[11] T. L. Saaty, "How to make a decision: The analytic hierarchy process," Interfaces, vol. 24, pp. 19-43, 1994.

[12] S. Anthony, The Innovator's Guide to Growth, Harvard Business Press, Boston, NY, USA, 2008. 
[13] L.Morris, InnovationMetrics:TheInnovation Process and How toMeasure It, An Innovation LabsWhite Paper, InnovationLab. LLC, 2008.

[14] H. A. Anton and C. Rorres, Elementary Linear Algebra, John Wiley \& Sons, New York, NY,USA, 9th edition, 2005.

[15] J. R. Sharma, Decision-making at A-Cat Corp., CaseWritting of Richard Ivey School of Business Foundation, 2011.

[16] T. L. Saaty,DecisionMaking for Leaders: The Analytic Hierarchy Process for Decisions in a Complex World, RWS, Pittsburgh, Pa, USA, 2001. 